\section{Condições de vida e saúde reprodutiva de adolescentes residentes na comunidade de Roda de Fogo, Recife}

\section{Life conditions and reproductive health of teenagers living in the Roda de Fogo community, Recife}

Ana Cláudia Figueiró 1

1Departamento de Pesquisa. Instituto Materno Infantil de Pernambuco (IMIP). Rua dos Coelhos, 300. Recife, PE, Brasil. CEP: 50.070-550. grupo.avaliacao@imip.org.br

\begin{abstract}
Objectives: to describe pregnancy and maternity of adolescents between 10 and 19 years old living in the Roda de Fogo community relating it to social and family conditions.

Methods: descriptive census, cross-sectional study using data of the Basic Information Attention System. Dependent variables: pregnant or adolescent mothers. Independent variables related to adolescents: Sex, age, education, and job. Related to family: home, job and type of jobs of parents, number of people living in the house, number of rooms, electricity and participation in community groups. The $\chi^{2}$ test and the odds ratio were used to calculate variables association.

Results: 88,0\% of adolescents were in school and $7,8 \%$ held jobs. The proportion of mothers living in the same house is higher than fathers living in the same home. $91,6 \%$ of parents and $54,3 \%$ of mothers held jobs. $31,1 \%$ of the families belonged to community groups. In the age group of 15 to 19 years old, $3,8 \%$ of the adolescents were pregnant and 11,9\% were mothers.

Conclusions: family structure affects adolescents' lives in their condition of pregnancy or maternity. This condition is associated to dropping out of school, absence of father and/or mother from home, father/mother unemployment and less participation of family in community groups.
\end{abstract}

Key words Pregnancy in adolescence, Reproductive medicine, Family Health Program

\section{Resumo}

Objetivos: descrever a situação da gravidez $e$ maternidade em adolescentes de 10 a 19 anos, residentes na comunidade de Roda de Fogo, relacionando sua condição social e famíliar.

Métodos: estudo descritivo, censitário, transversal, utilizando dados do Sistema de Informação da Atenção Básica. Variáveis dependentes: adolescente grávida ou mãe. Variáveis independentes relacionadas ao adolescente: sexo, idade, escolaridade $e$ ocupação; relativas à família: domicílio, ocupação $e$, tipo de emprego dos pais número de residentes casa, cômodos, luz elétrica e participação em grupos comunitários. $O \chi^{2}$ e o odds ratio foram usados para calcular a associação das variáveis.

Resultados: 88,0\% dos adolescentes estudavam e 7,8\% trabalhavam. Maior proporção de mães do que de pais residiam no mesmo domicílio. 91,6\% dos pais e 54,3\% das mães trabalhavam. 31,1\% das famílias participavam de grupos comunitários. Na faixa de 15 a 19 anos 3,8\% das adolescentes estavam grávidas $e$ $11,9 \%$ eram mães.

Conclusões: a estrutura familiar repercute na vida dos adolescentes e na sua condição de gravidez ou maternidade. Esta condição está associada com o abandono da escola, a ausência do pai elou da mãe do domicílio, o desemprego paterno elou materno e a menor participação da família em grupos comunitários.

Palavras-chave Gravidez na adolescência, Medicina reprodutiva, Programa de Saúde da Família 


\section{Introdução}

A adolescência e a juventude, em geral, definidas em referência à faixa de idade que cobre de 10 a 19 anos para a adolescência e de 15 a 24 anos para a juventude, entrecruzam-se entre os 15 e 19 anos, dando origem aos denominados adolescentes jovens. Olhando separadamente o grupo de adolescentes, aqueles entre 15 e 19 anos representavam, segundo dados do censo de 2000, 17,7 milhões, equivalendo a $10,4 \%$ da população total do país, 1 e tendo sofrido um acréscimo de 3,3 milhões de indivíduos em relação à geração de 1980. O dimensionamento do crescimento absoluto dessa população é de fundamental importância no planejamento das políticas públicas para o conjunto da sociedade, devido à pressão social que ela irá exercer sobre a demanda por bens e serviços públicos e o acesso ao mercado de trabalho. ${ }^{2}$

Seria, no entanto, uma perspectiva limitada considerarmos que esse universo define-se unicamente pela faixa etária dos sujeitos, pois neste caso estaríamos admitindo que os jovens experimentam, de modo semelhante, os conflitos e as incertezas próprios dessa fase. Tal como a concebemos hoje, a adolescência e a juventude constituem-se em uma invenção cultural, resultante da interação dos processos de desenvolvimento biológico, mental e social dos indivíduos, historicamente construída e vivida de forma distinta por cada pessoa e também, pela mesma pessoa em momentos sucessivos - na dependência da sua idade, gênero, etnia, condição social e valores predominantes no seu meio cultural.3-5 No cotidiano das camadas populares, as necessidades próprias desta fase da vida, acrescidas pela falta de atendimento a necessidades básicas, podem ser acentuadas por relações sociais desiguais - entre gêneros, entre subgrupos culturais, etários e étnicos, e entre gerações - que irão construindo as práticas desses grupos.

Nesta fase da vida, em um contexto de competição de necessidades, vem ganhando destaque para o setor saúde o avanço da epidemia do HIV/AIDS, o crescimento da violência - tendo os jovens como autores e vítimas das ocorrências - e o aumento da incidência de gravidez. Estudos realizados nos últimos trinta anos apontam para o aumento da fecundidade das adolescentes, tanto na faixa de 10 a 14 anos quanto na de 15 a 19 anos, quando comparadas com as mulheres de 20 e mais anos de idade. A Pesquisa Nacional sobre Demografia e Saúde (PNDS), feita no Brasil em 1996, verificou que, durante o período do levantamento, $18 \%$ das jovens entre 15 e 19 anos já tinham iniciado sua vida reprodu- tiva, sendo que destas, $14,3 \%$ já eram mães de pelo menos um filho vivo - no Nordeste este percentual foi de $16,7 \%$ - e $3,7 \%$ estavam grávidas. 6 Constatou-se no país, de 1993 a 2000, um aumento de $18,4 \%$ nos partos de adolescentes entre 10 e 14 anos passando de $0,93 \%$ no primeiro ano da série para $1,29 \%$ no último ano, e de $17,2 \%$ nos partos daquelas entre 15 e 19 anos de idade, variando de $21,42 \%$ para $25,84 \%$, no mesmo período. 7

A situação descrita para o Recife indica para o período entre 1995 e 2000, segundo o Sistema de Informações de Nascidos Vivos (SINASC) da Secretaria Municipal de Saúde, 8 uma tendência ao crescimento no percentual de recém nascidos de adolescentes nas faixas de idade entre 10 a 14 anos e 15 a 19 anos, variando de $0,77 \%$ até $0,92 \%$ para a faixa mais nova, e de $21,69 \%$ a $23,46 \%$ para as adolescentes jovens.

A gravidez entre adolescentes, principalmente nas duas últimas décadas, desponta como um dos problemas mais importantes para os jovens, trazendo conseqüências indesejáveis, particularmente para aqueles pertencentes às camadas mais pobres da sociedade. Para os serviços e os profissionais de saúde, a sua emergência como problema de saúde vem exigindo um melhor entendimento sobre os elementos envolvidos na sua ocorrência, na busca de identificar modos de ação com maior potencial para o seu enfrentamento.

Grande parte dos estudos, no âmbito da saúde, tem como propósito estabelecer associações entre características tanto do indivíduo quanto do meio que, condicionando comportamentos sexuais de risco, podem aumentar a probabilidade de engravidar. Assim, um maior risco de gravidez é associado com a menarca em idades menores, o abandono da escola, a baixa auto-estima das jovens, a desestrutura familiar (especificamente a ausência do pai), a não participação regular em grupos religiosos, a influência de pares (afirmação da identidade masculina) e a falta ou a baixa qualidade da informação sobre métodos contraceptivos. Evidencia-se, ainda, um risco maior para as jovens pertencentes às camadas mais pobres da sociedade, com menos anos de estudo e que tenham iniciado a vida sexual mais cedo.8-14

Reitera-se esse evento como um grave problema de saúde pública, com o fato de sua ocorrência estar associada com aspectos negativos da vida e saúde das mães adolescentes e de seus filhos. Nesta direção, a gravidez é associada com uma maior frequiência de baixo peso ao nascer, um maior risco de morrer no primeiro ano de vida, uma mortalidade materna mais elevada e uma maior incidência de eclâmpsia, infecção urinária e anemia.10,15,16 No que 
se refere à vida social, aponta-se que as mães jovens têm maior probabilidade de serem pobres do que aquelas que foram mães em idade maiores; o divórcio e o abandono escolar são mais freqüentes, seus salários são consideravelmente mais baixos e a alta proporção de ilegalidade limita $o$ acesso aos direitos legais e ao cuidado da saúde.12,13

Olhando a gravidez na adolescência a partir de outros pontos de vista, pondera-se que para o grupo entre 15 e 19 anos de idade este crescimento é, também, decorrência do próprio crescimento absoluto da população de jovens, que se torna ainda mais visível neste período devido à queda abrupta da fecundidade entre as mulheres acima de 20 anos.17-19

Stern 20 em artigo sobre o tema, no México, considera a gravidez na adolescência como um problema em algumas circunstâncias, por exemplo, entre as meninas de 14 anos ou menos. Para aquelas entre 15 e 19 anos, as condições sociais e culturais da sua ocorrência têm muito mais peso que a idade e os fatores biológicos a ela relacionados. Coll ${ }^{21}$ considera o atraso para o início do pré-natal da gestante jovem o principal responsável pelas possíveis consequiências negativas sobre a saúde das mães e de seus filhos. Essa demora tem várias causas, envolvendo aspectos relativos à organização dos serviços, tais como, obstáculos para acesso ao atendimento e despreparo dos profissionais de saúde para lidar com a situação. E mais ainda, a inexperiência, a dependência e os receios das jovens que reforçam as suas dificuldades para enfrentar a família, o pai da criança e muitas vezes esperando uma solução "mágica" para a gestação. Outro aspecto apontado por Stern 20 refere-se a que a insistente menção desse evento como problema está vinculada a sua ocorrência em contextos normativos onde se supõe que não deveria ocorrer. Este é também o ponto de vista defendido por Reis 22 ao apreender nos textos produzidos sobre o tema a partir dos anos 60, a aura de rejeição e intolerabilidade social que envolve essa gravidez.

A visão preventivista, caracterizada pela capacidade de estabelecer o que é adequado para controlar os eventos de saúde a partir da identificação dos fatores de risco envolvidos na sua ocorrência, concebe a definição da gravidez na adolescência como problema de saúde pública. Como ressaltam Stern 20 e Reis, 22 os profissionais de saúde recorrem a este referencial quando, ao se defrontarem com as adolescentes, com o seu olhar clínico, atribuem à gravidez os qualificativos de 'enfermidade', 'doença' e 'epidemia', solicitando intervenções terapêuticas ou de normalização. Alheios aos limites deste enfoque, os profissionais que atendem aos segmentos populares, sobretudo aqueles inseridos nas Equipes de Saúde da
Família (ESF), têm exercitado, sobremaneira, tal modo de olhar.

Em uma outra perspectiva de práticas de saúde, a proposta de reorganização das ações básicas, através do Programa Saúde da Família (PSF) - implantado no país, pelo Ministério da Saúde em 1994, como estratégia de mudança do modelo de atenção à saúde, priorizando os grupos populacionais sob situação de risco e objetivando a territorialização e integralidade das ações - é, em nosso país, a que tem buscado uma maior aproximação à realidade social e cultural das camadas populares. A sua implantação deve ser precedida pela realização do diagnóstico da área de abrangência, pois é a partir da identificação das necessidades de saúde que propiciará atenção integral à saúde das famílias, desenvolvendo ações de promoção da saúde, prevenção de agravos e tratamento de doenças, em uma abordagem que contempla tanto o indivíduo quanto à coletividade. 23

Neste sentido, a identificação da preocupação dos profissionais das ESF com a alta incidência de gravidez entre os adolescentes e o seu desconhecimento sobre a realidade social dos jovens e de sua vida reprodutiva reforça a necessidade de uma análise das possibilidades, acima apontadas, que o PSF oferece para lidar com o problema. Há que considerar que aspectos importantes dessa realidade poderiam ser conhecidos utilizando-se os próprios dados gerados pelas equipes, mesmo com algumas limitações, como a reduzida quantidade de variáveis referentes aos jovens nos seus instrumentos.

Utilizando os dados produzidos através do Sistema de Informação da Atenção Básica, quando do cadastramento da população adscrita das Unidades de Saúde da Família (USF) de Roda de Fogo, o presente artigo propõe-se a descrever a situação da gravidez e da maternidade entre adolescentes de $10 \mathrm{e}$ 19 anos de idade, residentes nesta comunidade, relacionando-a com aspectos da condição social dos jovens e das suas famílias.

\section{Métodos}

A comunidade de Roda de Fogo, fundada em 1983, situa-se no município de Recife, PE, Brasil, sendo uma localidade de baixas condições de vida, onde residem, segundo dados do censo realizado pelas Equipes de Saúde da Família, 16.253 pessoas, das quais 2.189 são adolescentes entre 10 e 19 anos de idade, o que representa, aproximadamente, $13,5 \%$ da população total.24 Esta localidade conta com três Unidades de Saúde da Família onde atuam quatro ESF, cada uma delas formada por médico, enfer- 
meiro, auxiliar de enfermagem e seis agentes comunitários de saúde (ACS), dispondo também de uma dentista e um técnico de odontologia que atende a população adscrita de duas equipes de saúde.

Realizou-se um estudo descritivo, censitário, do tipo transversal utilizando os registros dos dados obtidos através da Ficha A (Ficha para Cadastramento das Famílias), adaptada pela Secretaria de Saúde do Recife a partir do instrumento elaborado para o Sistema de Informação da Atenção Básica. Estes dados, coletados pelos ACS no a no de 2000, foram atualizados em 2001, sob a supervisão dos médicos e enfermeiros.

Estudaram-se variáveis relacionadas ao adolescente: a) identidade social: sexo, idade, escolaridade e ocupação; e b) vida reprodutiva: adolescente grávida ou mãe; e às condições de vida da sua família: presença dos pais no domicílio, ocupação e tipo de emprego dos pais, número de pessoas residentes na casa, número de cômodos, existência de luz elétrica na residência e participação em grupos comunitários. A brevidade do treinamento a que foram submetidos os ACS e a falta de um manual de instruções para esclarecer quanto aos critérios a serem adotados na padronização do preenchimento de algumas variáveis da ficha cadastral, são limitações do estudo consideradas quanto à qualidade da coleta dos dados. Estas limitações, entretanto, não foram suficientes para inviabilizar o uso dos dados uma vez que enfermeiros e médicos das ESFs acompanharam todo o procedimento de cadastramento das famílias, discutindo as dúvidas e corrigindo os erros identificados.

Os dados foram digitados e analisados utilizando o programa Epi-info 6.0. Buscou-se, primeiramente, caracterizar a condição social dos adolescentes e, em seguida, encontrar as variáveis capazes de diferenciar os grupos, calculando a proporção de grávidas e de mães entre as residentes na comunidade e sua associação com as variáveis independentes selecionadas. Recorreu-se, para evidência de significância estatística, ao teste Qui-quadrado, verificando-se a probabilidade de estar grávida ou de ter filhos e pertencer à determinada categoria através do odds ratio (OR), considerando um intervalo de confiança de $95 \%$.

\section{Resultados}

Identificou-se (Tabela 1) um percentual superior de mães $(94,4 \%)$ em relação ao de pais $(76,4 \%)$ residindo no mesmo domicílio dos adolescentes. Ainda em relação aos pais, $91,6 \%$ dos pais e 54,3\% das mães estavam trabalhando na ocasião do cadastramento, em geral desenvolvendo atividades mal remuneradas que requerem pouca qualificação. Os pais com mais freqüência eram pedreiros $(15,8 \%)$, comerciantes $(10,2 \%)$ e auxiliares de serviços gerais $(7,0 \%)$, enquanto as mães eram empregadas domésticas $(52,2 \%)$, auxiliares de serviços gerais $(9,5 \%) \mathrm{e}$ comerciantes $(7,8 \%)$. Em 31,1\% destas famílias houve referência à participação em algum grupo comunitário. Com relação às condições de moradia, em $65,1 \%$ dos domicílios residiam de uma a cinco pessoas, $62,8 \%$ tinham entre cinco e oito cômodos e $94,5 \%$ dispunham de luz elétrica.

Uma proporção discretamente maior dos adolescentes entre 10 a $14 \operatorname{anos}(52,6 \%)$ e 15 a 19 anos de idade $(50,8 \%)$ é do sexo masculino. A Tabela 2 mostra que, na época em que foi realizado o levantamento, $88,0 \%$ dos pertencentes a este grupo populacional estavam matriculados no sistema formal de educação, sendo esta inserção expressivamente maior na faixa de 10 a 14 anos $(97,6 \%)$ quando comparada àquela de 15 a 19 anos $(77,3 \%)$. No grupo populacional entre 15 e 19 anos de idade, aproximadamente $14,0 \%$ estava trabalhando, sendo $9,6 \%$ do sexo masculino; $9,0 \%$ do total de jovens desse grupo que trabalhavam não estavam mais estudando e $14,0 \%$ não estudavam nem trabalhavam. Dos $22,5 \%$ de adolescentes cujas fichas cadastrais dispunham de informação sobre a série que estava sendo cursada, $53,8 \%$ freqüentavam da quinta a oitava série do ensino fundamental e apenas $33,8 \%$ daqueles entre 15 a 19 anos cursavam ou tinham concluído o nível médio (Tabela 3). 
Distribuição das variáveis relativas às condições sociais das famílias dos adolescentes.

\begin{tabular}{|c|c|c|}
\hline Variáveis & n & $\%$ \\
\hline \multicolumn{3}{|l|}{ Pai mora em casa $(N=2.008)$} \\
\hline Sim & 1.533 & 76,4 \\
\hline Não & 475 & 23,6 \\
\hline \multicolumn{3}{|l|}{ Pai trabalha $(N=1.785)$} \\
\hline Sim & 1.394 & 78,1 \\
\hline Não & 391 & 21,9 \\
\hline \multicolumn{3}{|l|}{ Ocupação do pai ( $N=1.395)$} \\
\hline Pedreiro & 220 & 15,8 \\
\hline Comerciante & 143 & 10,2 \\
\hline Auxiliar de serviços gerais & 98 & 7,0 \\
\hline \multicolumn{3}{|l|}{ Mãe mora em casa $(N=2.099)$} \\
\hline Sim & 1.981 & 94,4 \\
\hline Não & 118 & 5,6 \\
\hline \multicolumn{3}{|l|}{ Mãe trabalha $(N=1.977)$} \\
\hline Sim & 1.074 & 54,3 \\
\hline Não & 903 & 45,7 \\
\hline \multicolumn{3}{|l|}{ Ocupação da mãe $(N=1.078)$} \\
\hline Empregada doméstica & 563 & 52,2 \\
\hline Auxiliar de serviços gerais & 102 & 9,5 \\
\hline Comerciante & 84 & 7,8 \\
\hline \multicolumn{3}{|c|}{ Residentes no domicilio ( $N=2.189$ ) } \\
\hline 1 a 5 pessoas & 1.424 & 65,1 \\
\hline 6 a 10 pessoas & 706 & 32,2 \\
\hline 11 e mais pessoas & 59 & 2,7 \\
\hline \multicolumn{3}{|l|}{ Cômodos do domicílio $(N=2.147)$} \\
\hline 1 a 4 & 706 & 32,9 \\
\hline 5 a 8 & 1.374 & 64,0 \\
\hline 9 e mais & 67 & 3,1 \\
\hline \multicolumn{3}{|c|}{ Luz elétrica no domicilio ( $N=2.179)$} \\
\hline Sim & 2.069 & 94,9 \\
\hline Não & 110 & 5,0 \\
\hline \multicolumn{3}{|c|}{ Participação de familiares em grupos comunitários $(N=2.179)$} \\
\hline Sim & 677 & 31,1 \\
\hline Não & 1.502 & 68,9 \\
\hline
\end{tabular}

$\mathrm{N}=$ número total de adolescentes 
Distribuição de variáveis relativas as condições sociais dos adolescentes, segundo a faixa de idade e o sexo*.

\begin{tabular}{|c|c|c|c|c|c|c|c|c|c|c|c|}
\hline \multirow{3}{*}{ Idade e sexo } & \multicolumn{5}{|c|}{ Estuda } & \multicolumn{5}{|c|}{ Não estuda } & \multirow{3}{*}{ p } \\
\hline & \multicolumn{2}{|c|}{ Trabalha } & \multicolumn{2}{|c|}{ Não trabalha } & \multirow{2}{*}{$\begin{array}{c}\text { Total } \\
\mathrm{n}\end{array}$} & \multicolumn{2}{|c|}{ Trabalha } & \multicolumn{2}{|c|}{ Não trabalha } & \multirow{2}{*}{$\begin{array}{c}\text { Total } \\
n\end{array}$} & \\
\hline & $\mathrm{n}$ & $\%$ & $\mathrm{n}$ & $\%$ & & $\mathrm{n}$ & $\%$ & $\mathrm{n}$ & $\%$ & & \\
\hline \multicolumn{12}{|l|}{$10-14$ anos } \\
\hline Masculino & 3 & 0,5 & 569 & 99,5 & 572 & 1 & 9,1 & 10 & 90,9 & 11 & \\
\hline Feminino & 1 & 0,2 & 509 & 99,8 & 510 & - & 0 & 15 & 100,0 & 15 & \\
\hline Subtotal & 4 & 0,4 & 1.078 & 99,6 & 1.082 & 1 & 3,8 & 25 & 96,2 & 26 & $>0,05 * *$ \\
\hline \multicolumn{12}{|l|}{$15-19$ anos } \\
\hline Masculino & 33 & 8,4 & 362 & 91,6 & 395 & 62 & 57,4 & 46 & 42,6 & 108 & \\
\hline Feminino & 16 & 4,3 & 354 & 95,7 & 370 & 27 & 23,1 & 90 & 76,9 & 117 & \\
\hline Subtotal & 49 & 6,4 & 716 & 93,6 & 765 & 89 & 39,6 & 136 & 60,4 & 225 & $<0,001 * * *$ \\
\hline \multicolumn{12}{|l|}{ Total } \\
\hline Masculino & 36 & 3,7 & 931 & 96,3 & 967 & 63 & 52,9 & 56 & 47,1 & 119 & \\
\hline Feminino & 17 & 1,9 & 863 & 98,1 & 880 & 27 & 20,5 & 105 & 79,5 & 132 & \\
\hline Subtotal & 53 & 2,9 & 1.794 & 97,1 & 1.847 & 90 & 35,9 & 161 & 64,1 & 251 & $<0,001 * * *$ \\
\hline
\end{tabular}

* Exclui 91 casos sem informação, ** Teste exato de Fisher (comparação entre os subtotais), *** Teste $\chi^{2}$ (comparação entre os subtotais)

Tabela 3

Distribuição dos graus de escolaridade segundo a faixa de idade.*

\begin{tabular}{|c|c|c|c|c|c|c|c|c|c|}
\hline \multirow{3}{*}{ Idade } & \multicolumn{8}{|c|}{ Escolaridade } & \multirow{3}{*}{ Total } \\
\hline & \multicolumn{2}{|c|}{ Alfabetizado } & \multicolumn{2}{|c|}{ Primeira a quarta série } & \multicolumn{2}{|c|}{ Quinta a oitava série } & \multicolumn{2}{|c|}{ Segundo grau } & \\
\hline & $\mathrm{n}$ & $\%$ & $\mathrm{n}$ & $\%$ & $\mathrm{n}$ & $\%$ & $\mathrm{n}$ & $\%$ & \\
\hline $10-14$ anos & 3 & 1,2 & 104 & 41,4 & 141 & 56,2 & 3 & 1,2 & 251 \\
\hline $15-19$ anos & 7 & 2,9 & 29 & 12,0 & 124 & 51,2 & 82 & 33,8 & 242 \\
\hline Total & 10 & 2,0 & 133 & 27,0 & 265 & 53,8 & 85 & 17,2 & 493 \\
\hline
\end{tabular}

* Informação disponível em $22,5 \%$ das fichas de cadastramento. 
Acerca da vida reprodutiva, $2,1 \%$ das adolescentes residentes em Roda de Fogo estavam grávidas no momento do cadastramento. Olhando separadamente os dois grupos etários, verifica-se que a incidência da gravidez entre as jovens de 15 a 19 anos foi de $3,8 \%$, significando quase a totalidade dos casos de gravidez ocorridos neste segmento da população. Observando-se o grupo como um todo se encontrou que $6,1 \%$ das adolescentes já eram mães, porém, entre aquelas de 15 a 19 anos este percentual foi de $11,9 \%$. (Tabela 4). Não houve nenhum registro de pai adolescente.
A condição de estar grávida ou de ser mãe estava fortemente associada com o abandono da escola pela jovem, com a ausência do pai e/ou da mãe do domicílio onde mora a jovem, com o desemprego paterno e/ou materno (associação ainda mais forte quando se leva em conta a condição de trabalho do pai) e com uma menor participação da família em grupos comunitários. A condição de trabalho da jovem não apresentou associação com a gravidez ou maternidade, cabendo ressaltar o pequeno número daquelas com trabalho remunerado na comunidade. (Tabela 5).

Tabela 4

Distribuição das adolescentes segundo a condição de gravidez ou maternidade e a faixa de idade.

\begin{tabular}{|c|c|c|c|c|c|c|c|c|}
\hline \multirow{3}{*}{ Idade } & \multicolumn{4}{|c|}{ Gravidez* } & \multicolumn{4}{|c|}{ Maternidade } \\
\hline & \multicolumn{2}{|c|}{ Sim } & \multicolumn{2}{|c|}{ Não } & \multicolumn{2}{|c|}{ Sim } & \multicolumn{2}{|c|}{ Não } \\
\hline & $\mathrm{n}$ & $\%$ & $\mathrm{n}$ & $\%$ & $\mathrm{n}$ & $\%$ & $\mathrm{n}$ & $\%$ \\
\hline $10-14(n=536)$ & 2 & 0,4 & 534 & 99,6 & 2 & 0,4 & 534 & 99,6 \\
\hline $15-19(n=520)$ & 20 & 3,8 & 500 & 96,2 & 62 & 11,9 & 458 & 88,1 \\
\hline Total $(n=1.056)$ & 22 & 2,1 & 1.034 & 97,9 & 64 & 6,1 & 992 & 93,9 \\
\hline
\end{tabular}

* Seis grávidas já eram mães 
Distribuição das adolescentes entre 15 e 19 anos de idade, conforme à condição de gravidez ou maternidade, em relação à sua situação social e da família.

\begin{tabular}{|c|c|c|c|c|c|c|c|}
\hline \multirow[t]{2}{*}{ Condição social } & \multicolumn{2}{|c|}{$\begin{array}{l}\text { Adolescentes não } \\
\text { grávidas ou mães } \\
\qquad(N=520)\end{array}$} & \multicolumn{2}{|c|}{$\begin{array}{l}\text { Grávidas ou mães } \\
\qquad(\mathbf{N}=76)\end{array}$} & \multirow[t]{2}{*}{ OR } & \multirow[t]{2}{*}{ IC95\% } & \multirow[t]{2}{*}{$p^{*}$} \\
\hline & $\mathrm{n}$ & $\%$ & $\mathrm{n}$ & $\%$ & & & \\
\hline \multicolumn{8}{|l|}{ Estuda } \\
\hline Sim & 349 & 67,1 & 21 & 27,6 & & & \\
\hline Não & 78 & 15,0 & 41 & 53,9 & 8,74 & $4,72-6,28$ & $\mathrm{p}<0,001$ \\
\hline Sem informação & 93 & 17,9 & 14 & 18,4 & & & \\
\hline \multicolumn{8}{|l|}{ Trabalha } \\
\hline Sim & 42 & 8,1 & 9 & 11,8 & & & \\
\hline Não & 402 & 77,3 & 67 & 88,2 & 0,78 & $0,34-1,80$ & $p=0,662$ \\
\hline Sem informação & 76 & 14,6 & - & - & & & \\
\hline \multicolumn{8}{|l|}{ Pai mora em casa } \\
\hline Sim & 301 & 57,9 & 24 & 31,6 & & & \\
\hline Não & 112 & 21,5 & 33 & 43,4 & 3,70 & $2,02-6,78$ & $p<0,001$ \\
\hline Sem informação & 107 & 20,6 & 19 & 25,0 & & & \\
\hline \multicolumn{8}{|l|}{ Pai trabalha } \\
\hline Sim & 269 & 51,7 & 19 & 25,0 & & & \\
\hline Não & 85 & 16,3 & 35 & 46,1 & 5,83 & $3,05-11,23$ & $p<0,001$ \\
\hline Sem informação & 166 & 31,9 & 22 & 28,9 & & & \\
\hline \multicolumn{8}{|l|}{ Mãe mora em casa } \\
\hline Sim & 398 & 76,5 & 45 & 59,2 & & & \\
\hline Não & 31 & 6,0 & 17 & 22,4 & 4,85 & $2,36-9,92$ & $\mathrm{p}<0,001$ \\
\hline Sem informação & 91 & 17,5 & 14 & 18,4 & & & \\
\hline \multicolumn{8}{|l|}{ Mãe trabalha } \\
\hline Sim & 240 & 46,2 & 24 & 31,6 & & & \\
\hline Não & 181 & 34,8 & 47 & 61,8 & 2,60 & $1,49-4,56$ & $p<0,001$ \\
\hline Sem informação & 99 & 19,0 & 5 & 6,6 & & & \\
\hline \multicolumn{8}{|c|}{ Familia participa em grupos comunitários } \\
\hline Sim & 160 & 30,8 & 14 & 18,4 & & & \\
\hline Não & 282 & 54,2 & 62 & 81,6 & 2,51 & $1,32-4,86$ & $p<0,001$ \\
\hline Sem informação & 78 & 15,0 & - & - & & & \\
\hline
\end{tabular}

* Teste $\chi^{2}$ 


\section{Discussão}

Dos pontos de vista social e econômico, as famílias dos adolescentes residentes em Roda de Fogo apresentam condições semelhantes àquelas encontradas entre os grupos que vivem em áreas pobres no Nordeste do país. Isto é, altas proporções de desemprego e de subemprego, quantidade expressiva de mulheres participando do sustento da família, abandono da escola e poucas oportunidades para os jovens conseguirem o primeiro emprego. 25 Pode-se supor, levando em conta as atividades mais citadas por mães e pais - $15,8 \%$ dos pais eram pedreiros e $52,2 \%$ das mães, empregadas domésticas - que as suas remunerações não ultrapassem em muito o salário mínimo vigente no país (atualmente, $\mathrm{R} \$ 200,00)$, sendo difícil estimar o ganho obtido nas atividades autônomas ou de biscate, ou nas atividades remuneradas realizadas na própria residência, como lavagem de roupa e costura. Verificando-se os dados sobre emprego e renda para o estado de Pernambuco, segundo a Pesquisa Nacional por Amostra de Domicílios (PNAD), 25 observa-se que a situação das mulheres trabalhadoras é sempre mais desfavorável do que a do homem - o rendimento médio mensal das mulheres é menor em todas as faixas de renda, com exceção apenas daquelas que recebem mais de 20 salários mínimos. A participação em grupo religioso representou quase a totalidade dos grupos comunitários citados pelas famílias, significando $92,0 \%$.

A grande quantidade de adolescentes de ambos os sexos que estavam freqüientando a escola na comunidade, em especial nas faixas de idade mais novas, é um dado que precisa ser valorizado. Para o país segundo dados da PNDS, 6 o percentual de freqüência escolar entre os adolescentes na faixa de 15 a 19 anos de idade, residentes em área urbanas, foi de $69 \%$ para as mulheres e $50,1 \%$ para os homens, percentuais que estão muito abaixo dos identificados no estudo. Quanto a este aspecto pode-se considerar que os resultados verificados em Roda de Fogo são concordantes com estudos sobre juventude e condições de vida, que associam o crescimento na proporção de jovens vinculados à escola com a valorização da escolarização feita por eles e suas famílias, principalmente nos centros urbanos.2,26 Para esses autores, o desinteresse e o abandono da escola aparece, com mais freqüência, entre os adolescentes jovens (entre 15 e 19 anos) como conseqüência da pouca condição que esta oferece para atender às necessidades sociais desse grupo, mais especificamente de profissionalização. Porém, e principalmente entre os mais novos, a escola apresenta- se como a possibilidade de ampliação das oportunidades futuras e um importante espaço de socialização - um dos únicos disponíveis, além das igrejas dada a falta de espaços públicos seguros e opções de lazer. Outro fator que, provavelmente, favoreceu a expressiva presença de adolescentes freqüentando a escola nesta comunidade foi a existência de escolas públicas de ensino fundamental e médio, estaduais e municipais. De fato a ausência e ou distância das escolas das residências é um importante motivo para o abandono escolar conforme a PNDS. 6

No presente estudo evidencia-se, ainda, que a inadequação entre a série escolar e a idade é um elemento expressivo nesta população, indicando longa permanência nos primeiros anos do ciclo escolar - e, ademais, isto não significando a aquisição dos conhecimentos esperados para este período da vida levando ao desinteresse do aluno e sendo considerando um motivo importante para o abandono escolar. ${ }^{27}$

Dos adolescentes jovens entre 15 a 19 anos de idade em Roda de Fogo, 13,9\% estão inseridos no mercado de trabalho. Se considerarmos a idade de 18 anos como referência para o ingresso na vida adulta (maioridade), e quando os jovens estariam finalizando o ensino fundamental, aqueles com 18 e 19 anos (17,4\%, em Roda de Fogo) seria de esperar que ingressassem no mercado de trabalho. Embora não se chegue a uma conclusão sobre se seria recomendável ou não que os adolescentes jovens estivessem exercendo função remunerada nessa faixa etária, os estudos de Madeira e Rodrigues ${ }^{2}$ e de Minayo et al. 26 apontam que, para eles, o trabalho não se constitui em um problema, sendo desejado e considerado mesmo necessário para que possam acumular experiência profissional. Os autores concordam, ainda, quando afirmam que muitos não abandonariam seus estudos desde que pudessem conciliar o trabalho com o horário noturno na escola. Chama a atenção o fato de que, dos 225 adolescentes que não estudam, $60 \%$ não estão também trabalhando, sendo essa proporção ainda maior entre as mulheres, $76,9 \%$. Segundo Arias, 28 o desemprego é uma forma de exclusão que adquire proporções preocupante entre a população jovem das áreas urbanas de todas as regiões do país, atingindo principalmente o grupo etário de 15-19 anos, o sexo feminino e as famílias de mais baixa renda.

Neste estudo observou-se, ainda, um percentual de grávidas do primeiro filho na faixa etária de 15 a 19 anos similar ao constatado pelo estudo nacional da PNDS, $63,8 \%$ e $3,7 \%$, respectivamente, e uma proporção de mães na mesma faixa de idade menor do que à verificada no estudo acima, $11,9 \%$ e $14,3 \%$. Essa diferença pode estar refletindo a fecundidade 
mais elevada da área rural do país, para o estudo da PNDS, quando comparada à dos centros urbanos.

O que podemos identificar neste estudo foi uma prevalência de gravidez e de maternidade menor entre as adolescentes cujo pai e mãe residiam no domicílio, bem como, entre a que estavam trabalhando. A participação da família em grupos religiosos (o mais freqüente grupo comunitário da área) parece favorecer o adiamento do início da vida reprodutiva, estando associada a uma menor prevalência deste evento, tendo já sido referido em outros estudos como condição protetora da gravidez na adolescência.9,29

A associação entre a baixa escolaridade e a gravidez e ou maternidade de adolescentes tem sido demonstrada em vários estudos, indicando sempre a maior proporção de grávidas e mães entre as jovens com menos tempo de estudo.6,16,17 A conclusão, muitas vezes imediata, de que a gravidez é causa do abandono escolar e que portanto a sua prevenção adiaria a decisão de abandonar a escola já não é tão óbvia quanto faz supor, pois alguns estudos indicam que boa parte das gestantes e mães adolescentes não estavam mais freqüentando a escola antes desse evento. ${ }^{13,21}$

O significado da relação entre gravidez na adolescência e escolaridade das mulheres nessa faixa de idade ainda merece ser melhor esclarecido. Estudos indicam que há uma diminuição do percentual de adolescentes grávidas ou já mães à medida que aumenta o nível de instrução. Verifica-se que entre as mulheres que não tiveram filhos há um ganho de escolaridade crescente à medida que aumenta a idade, enquanto aquelas com filhos iniciam o estudo em um patamar mais baixo, mantendo menor escolaridade em todas as idades e a escolaridade não aumentando a partir dos 16 anos. 13

O que parece evidente neste e em outros estudos, é a maternidade e a constituição da família afetarem a escolarização das mães por causa da passagem abrupta em uma fase da vida da mulher jovem para outra, obrigando-a a assumir papéis da vida adulta muitas vezes incompatíveis com os estudos. 13 Além disso, a insuficiente condição da escola para incluir uma gestante ou mãe adolescente como estudante regular - a qual sofre os preconceitos e empecilhos de professores ou da direção - ou ainda a pouca flexibilidade quanto aos horários e formas de participação em sala de aula, contribuem para a desistência da jovem grávida ou mãe continuarem freqüentando a escola. $13,21,30$

\section{Conclusões}

Considerando que a ocorrência da gravidez e maternidade entre adolescentes na comunidade de Roda de Fogo é expressiva, a situação descrita merece mais do que o espanto ou a indignação com que muitos profissionais de saúde referem-se a ela. Pôdese verificar que há um potencial pouco aproveitado no âmbito dos serviços de saúde. O uso dos dados gerados pelo próprio Programa de Saúde da Família produzindo informação contínua e de qualidade, permitiria aos profissionais e gestores um planejamento das ações de saúde de modo mais ágil e focado na realidade dos grupos sociais atendidos e acompanhados pelo programa. Mas além, e tão importante quanto, ofereceria a possibilidade do envolvimento e participação efetiva dos setores interessados na produção de melhorias destinadas às pessoas, aos grupos e ao ambiente, na sua área de abrangência. Poderia, desse modo, constituir-se não apenas em um instrumento de organização e gerência do setor da saúde mas num importante recurso para o diálogo entre os serviços e seus profissionais, os usuários, os residentes e os muitos setores públicos e sociais presentes nas comunidades assistidas, capazes de contribuir para conquistas de saúde que são desejadas por todos.

\section{Agradecimentos}

À orientação da Dra. Katia Feliciano e à Secretaria de Políticas de Saúde do Ministério da Saúde pelo apoio financeiro. 


\section{Referências}

1. IBGE (Instituto Brasileiro de Geografia e Estatística). Censo, 2000. Disponível em: http://www.ibge.gov.br. [12 mar 2002].

2. Madeira FR, Rodrigues EM. Recado dos jovens: mais qualificação. In: Ministério do Planejamento. Comissão Nacional de População e Desenvolvimento. Jovens acontecendo na trilha das políticas das políticas. Brasília, DF: Ministério do Planejamento; 1998. p. 427-96.

3. Margulis M. Juventud: una aproximación conceptual. In: Burak SD, organizador. Adolescencia y juventud em America Latina. Costa Rica: Libro Universitario Regional; 2001. p. 41-56.

4. Quapper KD. Juventud o juventudes? Acerca de como mirar y renirar a las juventudes de nuestro continente. In: Burak SD, organizador. Adolescencia y juventud em America Latina. Costa Rica: Libro Universitario Regional; 2001. p. 57-74.

5. Narvaez RO. Saúde integral do adolescente e sua abordagem multidisciplinar. Adolesc Latinoam 1997; 1: 510.

6. BEMFAM (Sociedade Civil Bem-Estar Familiar no Brasil). Adolescentes, jovens e a pesquisa nacional sobre demografia e saúde: um estudo sobre fecundidade, comportamento sexual e saúde reprodutiva. Rio de Janeiro: BEMFAM; 1999.

7. Ministério da Saúde. Nascimento por residência da mãe, segundo a idade da mãe: Recife, 1995 a 1999. Disponível em: http://www.saude.gov.br/datasus. [9 Dec 2001].

8. Recife. Secretaria de Saúde. Crianças do Recife: perfil de nascimentos, 1995-2000. Recife, Secretaria Municipal de Saúde; 2001.

9. Marques NM. Adolescent pregnancy social and family risk factors [master's dissertation]. London: University of London; 1989.

10. Camarano AA. Fecundidade e anticoncepção na população de 15 a 19 anos. In: Vieira EM, Fernandes ME, Bailey P, McKay, A, organizadores. Anais do Seminário Gravidez na Adolescência. Rio de Janeiro: Associação Saúde da Família; 1998. p. 36-46.

11. Bruno ZV, Bailey PE. Gravidez em adolescentes no Ceará: maternidade ou aborto. In: Vieira EM, Fernandes ME, Bailey P, McKay, A, organizadores Anais do Seminário Gravidez na Adolescência. Rio de Janeiro: Associação Saúde da Família; 1998. p. 57-66.

12. Rigsby DC, Macones GA, Driscoll DA. Risk factors for rapid repeat pregnancy among adolescent mothers: a review of the literature. J Pediatr Adolesc Gynecol 1998; 11: 115-26.

13. Souza MMC. A maternidade nas mulheres de 15 a 19 anos como desvantagem social. In: Vieira EM, Fernandes ME, Bailey P, McKay, A, organizadores. Anais do Seminário Gravidez na Adolescência. Rio de Janeiro: Associação Saúde da Família; 1998 p. 74-91.

14. Alcântara R, Antunes A, Lessa F, Aquino T, Avelar I, Melo N. A reprodução na adolescência - os riscos da gestação para os envolvidos. Recife: Os autores; 1999.

15. Oliveira MW. Gravidez na adolescência: dimensões do problema. Cad Cedes 1998; 19 (45).
16. Gama SGN, Szwarcwakd CL, Leal MC, Theme Filha MM. Gravidez como fator de risco para o baixo peso ao nascer no município do Rio de Janeiro, 1996 a 1998. Rev Saúde Pública 2001; 35: 74-80.

17. Camarano AA. Fecundidade e anticoncepção da população jovem. In: Ministério do Planejamento. Comissão Nacional de População e Desenvolvimento. Jovens acontecendo na trilha das políticas das políticas. Brasília, DF: Ministério do Planejamento; 1998. p. 109-13.

18. Medrado B, Lira J. A adolescência "desprevenida" e a paternidade na adolescência: uma abordagem geracional e de gênero. Cad Juv Saúde Desenvol 1999; 1: 230-48.

19. Schkolnic S. Dinámica de la población y juventud en America Latina y el Cairbe. In: Burak SD, organizador. Adolescencia y juventud em America Latina. Costa Rica: Libro Universitario Regional; 2001. p. 309-23.

20. Stern C. El embarazo en la adolescencia como problema público: una visión crítica. Rev Salud Pública México 1997; 39: 137-43.

21. Coll A. Embarazo em adolescencia: quál es el problema? In: Burak SD, organizador. Adolescencia y juventud em America Latina. Costa Rica: Libro Universitario Regional; 2001. p. 425-45.

22. Reis AOA. Análise metafórico-metonímica do processo de constituição do pensamento da saúde pública acerca da adolescente grávida: os anos 60. Cad Saúde Pública 1998; 14 Supl 1: 115-23.

23. Ministério da Saúde. O trabalho do agente comunitário de saúde. Disponível em: http://www.saude.gov.br/sps. [21 Set 2001].

24. Recife. Sistema de Informação da Atenção Básica. Equipes de Saúde de Roda de Fogo. Recife, Secretaria Municipal de Saúde; 2001.

25. IBGE (Instituto Brasileiro de Geografia e Estatística) Pesquisa Nacional por Amostra de Domicílios, 1999. Disponível em: http://www.ibge.gov.br. [12 mar 2002].

26. Minayo MCS, Assis SG, Souza ER, Njaine K, Deslandes SF, Silva CMFP, Fraga PCP, Gomes R, Abramovay M, Waiselfisz JJ, Monteiro MCN. Fala galera: juventude, violência e cidadania na cidade do Rio de Janeiro. Rio de Janeiro: Garamond; 1999.

27. Sabóia AL. Situação educacional dos jovens. In: Ministério do Planejamento e Orçamento. Comissão Nacional de População e Desenvolvimento. Jovens acontecendo na trilha das políticas. Brasília, DF: Ministério do Planejamento e Orçamento; 1998. p. 499-515.

28. Arias AR. Avaliando a situação ocupacional e dos rendimentos do trabalho dos jovens entre 15 e 24 anos de idade na presente década. In: Ministério do Planejamento. Comissão Nacional de População e Desenvolvimento. Jovens acontecendo na trilha das políticas das políticas. Brasília, DF: Ministério do Planejamento; 1998. p. $519-41$

29. Madaleno M, Ojeda ENS. Situacion social de los adolescentes y jovens em América Latina. In: La salud del adolescente y del joven. Washington, DC: Organizacion Panamericana de la Salud (OPS); 1995. (Publicacion Científica, 552). 
30. Heilborn ML. Gravidez na adolescência: considerações preliminares sobre as dimensões culturais de um problema social. In: Vieira EM, Fernandes ME, Bailey P, McKay A, organizadores. Anais do Seminário Gravidez na Adolescência. Rio de Janeiro: Associação Saúde da Família; 1998. p. 47-56

Recebido em 3 de junho de 2002

Versão final reapresentada em 8 de agosto de 2002

Aprovado em 3 de setembro de 2002 